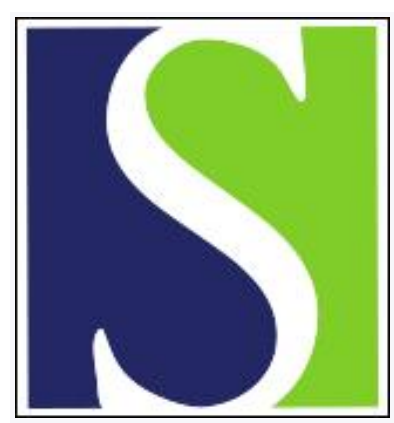

Scand J Work Environ Health 1986;12(4):395-399

https://doi.org/10.5271/sjweh.2123

Issue date: Aug 1986

Finger peripheral resistance during local cold provocation in vasospastic disease.

by Pyykko I, Kolari P, Farkkila M, Starck J, Korhonen O, Jantti V

This article in PubMed: www.ncbi.nlm.nih.gov/pubmed/3775329

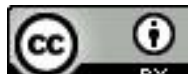




\title{
Finger peripheral resistance during local cold provocation in vasospastic disease
}

\author{
by Ilmari Pyykkö MD, ${ }^{1}$ Pertti Kolari, MSc, ${ }^{1}$ Markus Färkkilä, MD, ${ }^{2}$ Jukka Starck, $\mathrm{PhD},{ }^{1}$ \\ Olli Korhonen, $M D,{ }^{1}$ Ville Jäntti, $M D^{3}$
}

\begin{abstract}
PYYKKÖ I, KOLARI P, FÄRKKILÄ M, STARCK J, KORHONEN O, JÄNTTI V. Finger peripheral resistance during local cold provocation in vasospastic disease. Scand J Work Environ Health 12 (1986) 395-399. Finger systolic blood pressure (FSBP), finger arterial inflow (FAI), finger venous opening pressure (FVOP), and finger peripheral resistance (FPR) were evaluated in 56 workers exposed to chain-saw vibration. Twenty-one of the workers were free from vibration-induced white finger (VWF). In 17 subjects VWF had ceased; 12 of the subjects had active VWF; 6 subjects had Raynaud's disease. The subjects were examined in a supine position under thermoneutral conditions with strain-gauge plethysmography. Cold provocation of the finger caused a significant reduction in FSBP in the groups with Raynaud's disease and active VWF. The finger circulation of the subjects with active VWF and that of those with Raynaud's disease showed a significantly reduced FAI when compared with that of the symptom-free referents. Finger cooling produced a gradual reduction in the FVOP and a significantly increased FPR of the subjects with active VWF and in those with Raynaud's disease. FPR was already increased in the Raynaud's disease group at the beginning of the test, whereas it increased in the VWF group as the temperature fell. The results suggest that in Raynaud's disease the fault is in the level of activity of the sympathetic outflow and in VWF it is peripheral mechanisms controlling the vessel tone.
\end{abstract}

Key terms: arterial flow, finger systolic pressure, Raynaud's phenomenon, venous pressure.

During segmental cooling of the finger the local arteries show a prominent constriction in subjects with vasospastic diseases. This constriction results in a reduction in the systolic blood pressure of the finger. Evaluation of this parameter has therefore been employed in the diagnostic assessment of vibrationinduced white finger (VWF) and Raynaud's disease (1, 16, 23).

There is a well known connection between pressure, flow, and peripheral resistance. Flow is inversely related to peripheral resistance and directly related to pressure (7) (figure 1). Normally, peripheral resistance is regulated by the radius of the vessel, which causes, according to Poiseuille's law (21), a powerful effect on flow. Hitherto, the importance of the different factors determining blood circulation in patients with VWF and Raynaud's disease has not been known in detail.

The aim of the present report was to study, with a strain-gauge plethysmographic technique, the relationship between pressure, flow, and peripheral resistance to evaluate their reciprocal importance in causing vasospastic attacks in victims with VWF. For comparison a group of subjects with Raynaud's disease and a symptom-free group of healthy referents were examined.

I Institute of Occupational Health, Helsinki, Finland.

2 Helsinki University Central Hospital, Helsinki, Finland.

3 Tampere University Central Hospital, Tampere, Finland.

Reprint requests to: Dr I Pyykkö, Instiute of Occupational Health, Topeliuksenkatu 41 aA, SF-00250 Helsinki, Finland.

\section{Subjects and methods}

Fifty-six forest workers were selected from 206 forest workers studied in connection with the compulsory health examination in the area called Suomussalmi in northeast Finland. Twenty-one of the workers were free from VWF. Seventeen subjects had "recovered" from VWF and had not experienced any symptoms during at least the previous two years. Twelve of the subjects had active VWF. Six of the subjects had primary Raynaud's disease. The mean age, exposure to chain-saw vibration, and occupational disease history are shown in table 1.

A commercially available strain-gauge plethysmograph (Medimatic SP-2, Denmark) was used. From the subjects with VWF the recordings were taken from the most affected finger. A symptom-free finger on the opposite hand was used as reference in the standardization of the pressure parameter. During the test the blood circulation of the finger was arrested with a suprasystolic pressure of $250 \mathrm{~mm} \mathrm{Hg}(33331 \mathrm{~Pa}$ ) for 5 min by the placement of a cuff on the proximal

Table 1. Age and exposure to vibration of forest workers in the different disease groups. (RD = Raynaud's disease, $\mathrm{VWF}=$ vibration-induced white finger)

\begin{tabular}{lcclll}
\hline \multirow{2}{*}{ Group } & \multicolumn{2}{c}{ Age (years) } & & \multicolumn{2}{c}{ Exposure (h) } \\
\cline { 2 - 3 } \cline { 5 - 6 } & Mean & SD & & Mean & SD \\
\hline Current RD & 45.7 & 8.1 & & 14700 & 7200 \\
Previous WWF & 49.7 & 5.8 & & 16800 & 6300 \\
Current VWF & 47.1 & 7.5 & & 13100 & 7700 \\
Reference & 45.3 & 7.4 & & 16400 & 5000 \\
\hline
\end{tabular}


phalanx of the finger. The middle phalanx was simultaneously cooled for a period of $5 \mathrm{~min}$ to a temperature of $25,20,15,10$, or $5^{\circ} \mathrm{C}$. A miniature thermistor (model 46, Yellow Springs Instruments, United States)

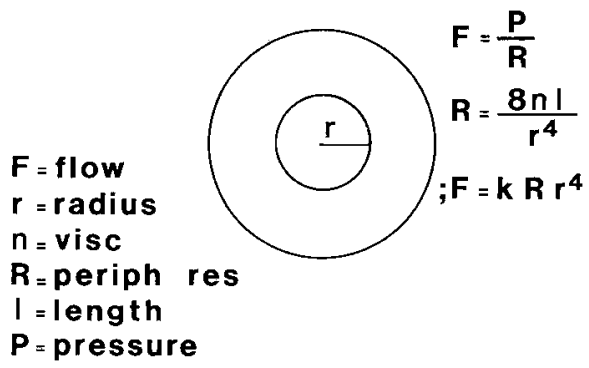

Figure 1. Relationship between flow, pressure and peripheral (periph) resistance (res). (visc $=$ viscosity)

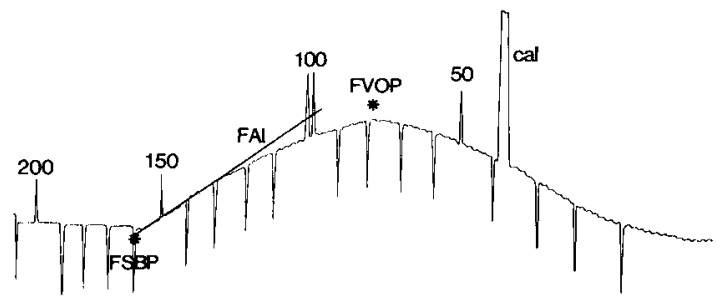

Figure 2. Strain-gauge plethysmography during the recording of finger circulation. Asterisks indicate the finger systolic blood pressure (FSBP) and the finger venous opening pressure (FVOP). The tangent of the recording shows the finger arterial inflow (FAI). $(\mathrm{cal}=$ calibration)

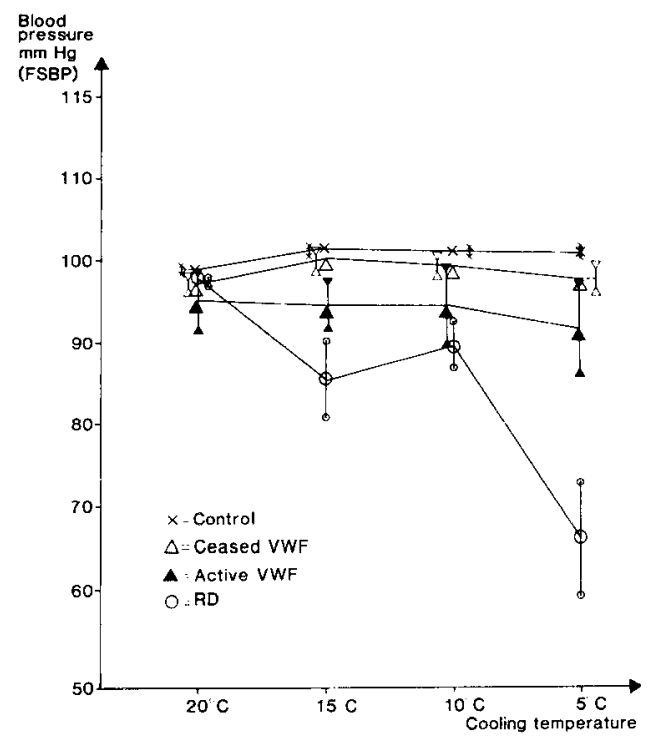

Figure 3. Finger systolic blood pressure (FSBP) in different groups of subjects during the cold provocation. Means and standard errors are shown. (Control $=$ referent, $V W F=v i$ bration-induced white finger, RD = Raynaud's disease, $1 \mathrm{~mm} \mathrm{Hg} \approx 133.322 \mathrm{~Pa}$ ) was placed below the cooling cuff. The measurement system closely resembled that used by Thulesius and his co-workers (23) and by Arneklo-Nobin (1).

Before the test the hands were warmed with hot water of $40-43^{\circ} \mathrm{C}$ for $10-15 \mathrm{~min}$. The subjects were placed supine and examined under thermoneutral conditions. After the recording of the base-line values, the finger with the most prominent symptoms of VWF was cooled at predetermined temperatures for $5 \mathrm{~min}$. The stimulus-free interval between the successive cooling periods was $5 \mathrm{~min}$.

From the recordings finger systolic blood pressure (FSBP), finger arterial inflow (FAI), and finger venous opening pressure (FVOP) were evaluated (figure 2). For calculations of the finger peripheral resistance (FPR) FAI was used to give an estimate of arterial inflow. For the driving pressure (DP) estimate, the difference between the FSBP and FVOP was used. The FPR was calculated for each subject at each temperature by the following formula:

$$
\mathrm{FPR}=(\mathrm{FSBP}-\mathrm{FVOP}) / \mathrm{FAI} \text {. }
$$

For standardization of the FSBP and FAI the following formula was used:

$$
\text { \% pressure }=\left(\mathrm{Pc}_{30} \times \mathrm{Pt} / \mathrm{P}_{30} \times \mathrm{Pc}_{\mathrm{t}}\right) \times 100,
$$

where $\mathrm{Pc}_{30}$ is the FSBP or FAI of the control finger at $30^{\circ} \mathrm{C}, \mathrm{Pc}_{\mathrm{t}}$ is the FSBP or FAI of the control finger at the cooling temperature (t), and $\mathrm{P}_{30}$ and $\mathrm{P}_{\mathrm{t}}$ are the FSBP or FAI of the cooled finger at comparable temperatures.

Student's t-test was used for the statistical analysis. The p-values calculated for different stimulus conditions were used in a second stage of the analysis to give summary statistics. The following formula was used: $\mathrm{T}=\log \mathrm{PJ}$, where $\mathrm{T}$ is distributed as the chi-square distribution with two degrees of freedom (4). When the p-value was $<0.05$, the difference was considered to be statistically significant.

\section{Results}

Cold provocation of the finger caused a gradual reduction in the finger systolic blood pressure in the groups with Raynaud's disease and active VWF $(p<0.001)$. No changes in this parameter were observed in the other groups of workers (figure 3). In the referents and in those with inactive VWF there was a compensatory pressure elevation, as occurs normally during moderate cooling (9).

The standardized finger circulation in the subjects with active VWF ( $<0.01)$ and those with Raynaud's disease $(p<0.001)$ showed a significantly reduced finger arterial inflow when compared with that of the symptom-free referents and those who had previously had VWF (figure 4). No difference was found between the referents and those who had previously had VWF. 


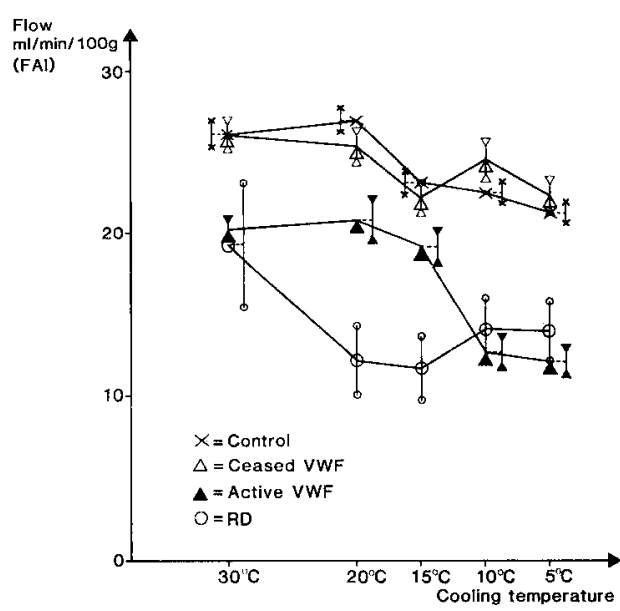

Figure 4. Finger arterial inflow (FAI) in the different groups of subjects during the cold provocation. Means and standard errors are shown. (Control $=$ referent, VWF $=$ vibration-induced white finger, $R D=$ Raynaud's disease, $\mathrm{ml} / \mathrm{min} / 100$ $\mathrm{g}=\mathrm{ml} \cdot \mathrm{min}^{-1} \cdot 100 \mathrm{~g}^{-1}$ )

The tone of the venous walls during ambient cooling was explored with an analysis of the finger venous opening pressure. Only the subjects with Raynaud's disease showed a significant reduction under thermoneutral conditions $(p<0.05)$. Finger cooling at different temperatures produced a gradual reduction in the subjects with active VWF and in those with Raynaud's disease (figure 5); the reduction was statistically highly significant for both groups $(\mathrm{p}<0.001)$.

Subjects with active VWF and those with Raynaud's disease had a significantly increased finger peripheral resistance $(p<0.01)$ (figure 6$)$. It was already increased in the Raynaud's disease group at the beginning of the test $(p<0.05)$, whereas it increased in the VWF group when the finger was cooled to 10 and $5^{\circ} \mathrm{C}$. In subjects with Raynaud's disease the reduction of the finger systolic blood pressure, together with the reduction of finger arterial inflow, powerfully changes this relationship and produces an apparently normal finger peripheral resistance when the finger is cooled.

\section{Discussion}

In the present study the analysis was based on a hypothesis that the vascular bed would consist of a rigid tube (7). Such a hypothesis oversimplifies the finger peripheral resistance evaluation and neglects simultaneously occurring changes in the length and patency of the vascular bed (15), as well as changes in blood viscosity (5). These changes may aggravate the peripheral resistance and cause the critical closure of the vessels sooner than can be estimated (21).

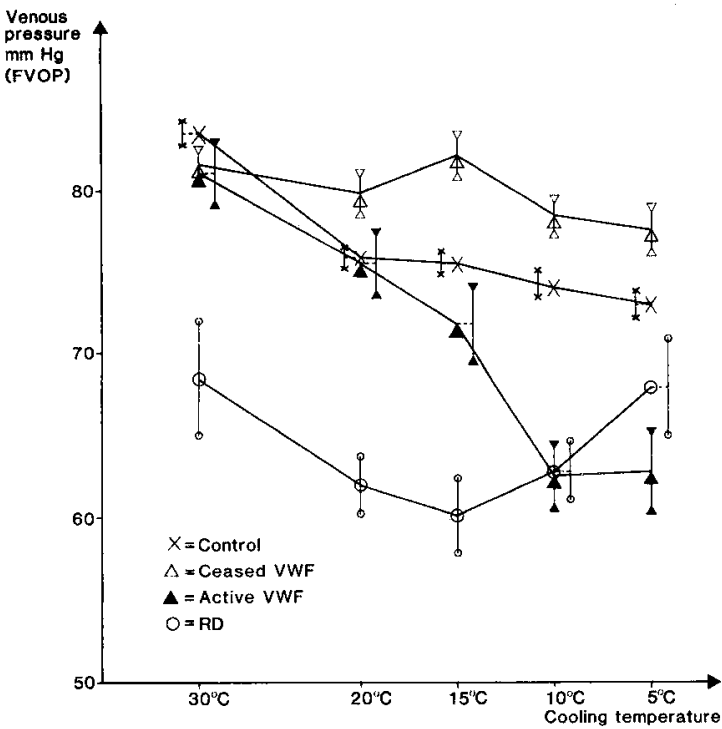

Figure 5. Finger venous opening pressure (FVOP) in the different groups of subjects during the cold provocation. Means and standard errors are shown. (Control = referent, VWF = vibration-induced white finger, $\mathrm{RD}=$ Raynaud's disease, $1 \mathrm{~mm}$ $\mathrm{Hg} \approx 133.322 \mathrm{~Pa})$

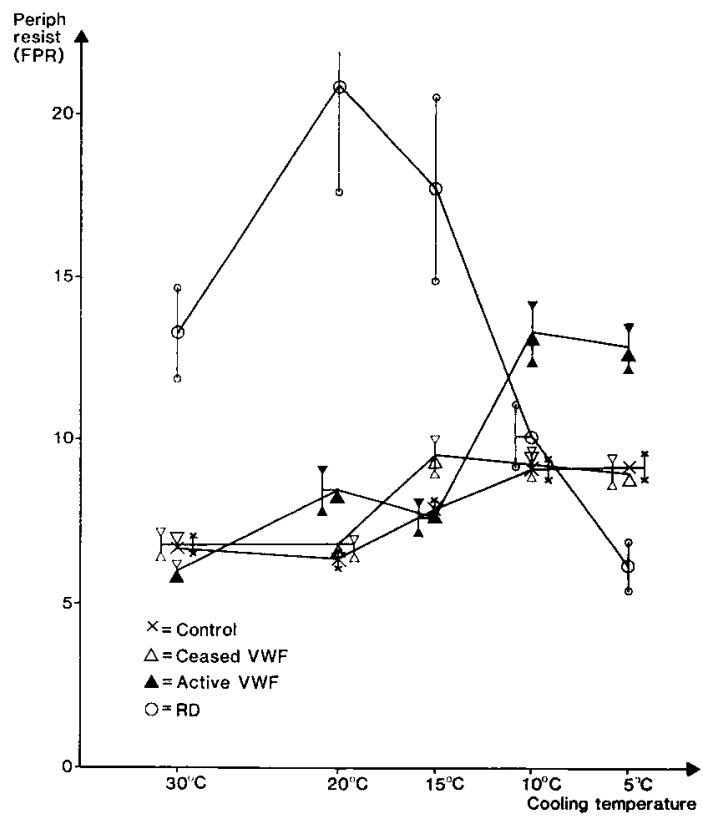

Figure 6. Finger peripheral (periph) resistance (resist) (FPR) in different groups of subjects during the cold provocation. Means and standard errors are shown. (Control = referent, $V W F=$ vibration-induced white finger, $R D=$ Raynaud's disease)

Furthermore, finger peripheral resistance is only an estimate of the true peripheral resistance because measurements of mean arterial pressure and arterial blood flow, a process that requires invasive measurements, ought to be determined for that purpose (7). Thus 
finger peripheral resistance must be regarded only as a crude estimate in the present work, and the results should be interpreted with some caution.

Nevertheless, moderate cooling produced changes in blood flow and pressure in subjects with VWF, and in those with Raynaud's disease the changes differed from those of the symptom-free referents. The reduction in the blood circulation could be best explained by an increase in peripheral resistance. Thus the variable which best predicts a vasospastic attack seems to be an increase in finger peripheral resistance.

\section{Role of vascular tone and peripheral receptors in the etiology of vibration-induced white finger and finger peripheral resistance}

After local heating of the skin, the finger peripheral resistance in subjects with Raynaud's disease was increased in contrast to that of the subjects with active VWF. The differences between forestry workers with VWF and those with Raynaud's disease may reflect differences in the basic mechanism causing these disorders. The output of the autonomic nervous system may be increased in Raynaud's disease, since the finger peripheral resistance was increased among these subjects even after their hands were heated and the possible local vasoconstrictive mechanisms were eliminated. Thus enhanced sympathetic nervous activity may play a primary role in producing attacks of Raynaud's phenomenon in subjects with Raynaud's disease (9). A cooling of the finger may potentiate the output of the autonomic nervous system by intervening with the receptor activity, the result being a reduced finger arterial inflow and increased finger peripheral resistance (24).

The subjects with VWF had normal finger peripheral resistance under thermoneutral conditions, a phenomenon indicating an apparently normal intrinsic activity of the autonomic nervous system. This finding is in contrast with the idea of autonomic neuropathy of the central nervous system (13), and it supports the hypothesis of a "local fault" in the vessel wall suggested by Lewis \& Pickering (12). However, the "local fault" may not indicate an enhanced sensitivity of smooth muscles to cold but instead a changed affinity of the sympathetic receptors in the vessels to cold, as is proposed to occur in some cases of Raynaud's disease (24).

Cooling of the vessel wall sensitizes the noradrenergic receptors and delays the reuptake of the transmittor substances $(11,24)$ and therefore increases the strength of the constriction. It is quite possible that the increase of finger peripheral resistance in the VWF subjects was due to an aggravated sensitivity of the sympathetic receptors (2). Thus the output of the sympathetic nervous system assists the release of the symptoms. Interestingly, Olsen and colleagues (18) recently showed that zero finger systolic blood pressure can be provoked in subjects with VWF only through the sympathetic nervous pathways. Thus aggravated vasospasms of VWF closely mimicking the vasospasms of Raynaud's disease can be observed during aggravation of the sympathetic outflow (20).

\section{Additional factors contributing to the vasospasms of vibration-induced white finger and Raynaud's disease}

In spite of the diversity of etiologic mechanisms several factors may contribute to the onset of an attack in VWF and Raynaud's disease. Augmentation of sympathetic tone either through emotion or cooling favors an attack of VWF and Raynaud's disease $(8,20)$. Exposure to various drugs, eg, nicotine, augments vasoconstriction (14). Thus heavy smokers suffer more frequently from VWF than nonsmokers (19). Replacement of subcutaneous tissue by callosities, as occurs with prolonged vibration (22), reduces the size of the capillary bed and the apparent length of the vascular bed (figure 1). Gripping a tool (eg, chain saw) partially blocks the capillary beds of the fingers and increases the transmural pressure $(7,21)$, further reducing blood flow.

An increase in the venous tone of the finger in the cold reduces the perfusion pressure and reduces the arterial inflow through the so-called venoarterial reflex (21). In addition increased venous wall tension changes the buffer capacity of the capillary bed (22) and may further promote finger peripheral resistance and retard circulation.

Vasoconstriction with venoconstriction also produces hemoconcentration in the capillary bed $(5,15)$, which increases the viscosity and augments finger peripheral resistance $(3)$. Some reports $(10,17)$ have indicated that subjects with VWF may have higher viscosity of the circulating blood than subjects without VWF. Allegedly, persons with high or pathological viscosity tend to be selected into the group with VWF. Thus changes in viscosity are rather a contributory than an etiologic factor in VWF.

Structural changes have also been found in workers exposed to vibration. Intimal thickening and hypertrophy of the medial layer are the most characteristic findings. Since these factors may encroach on the lumina of the digital arteries, such changes also promote the affinity of vibration-exposed workers for VWF. Since the intimal layer and cooperation between the intimal and medial layer contribute to the local control of tone (6), such changes may also disturb this cooperation and augment vasoconstriction.

Thus in a vasospastic disease such as VWF or Raynaud's disease several factors contribute to the vasospasms which can normally be compensated by local vasodilatory mechanisms (25). An attack of VWF may be regarded as the result of a failure of autoregulation to overcome an excessive increase in peripheral resistance. 


\section{Conclusions}

Local and general cold provocation causes flow and pressure reduction in the digital arteries. A simultaneous increase in venous tone causes a venoconstriction that worsens the perfusion. Other factors may also contribute to an increase in finger peripheral resistance. Vasoconstriction with venoconstriction leads to hemoconcentration and increases blood viscosity and thus increases finger peripheral resistance. The closing of arteriovenous anastomoses reduces finger circulation and leads to a decrease in the length of the circulatory bed. This decrease further worsens digital perfusion. Compression of a handle of a tool augments these physiological changes. The best parameter predicting VWF seems to be an increase in finger peripheral resistance at low temperatures.

\section{References}

1. Arneklo-Nobin B. The white cold hand. University of Lund, Lund 1983 (Department of surgery, bulletin no 31). (Doctoral dissertation).

2. Azuma T, Ohhashi T, Sakaguchi M. An approach to the pathogenesis of "white finger" induced by vibratory stimulation: Acute but sustained changes in vascular responsiveness of canine mindlimb to norardenaline. Cardiovasc Res 14 (1980) 725-730.

3. Blunt RJ, George AJ, Hurlow RA, Strachan CJL, Stuart J. Hyperviscosity and thrombotic changes in idiopathic and secondary Raynaud's phenomenon. Br J Haematol 45 (1980) 651-658.

4. Cox DR, Hinkley DV. Theoretical statistics. Chapman and Hall, London 1974, pp 80-82.

5. Fagrell B, Intaglietta M, Östergren J. Relative hematocrit in human skin capillaries and its relation to capillary blood flow velocity. Microvasc Res 20 (1980) $327-335$.

6. Furchgott FR. The requirement for endothelial cells in the relaxation of arteries by acetylcholine and some other vasodilators. Trends Pharmacol Sci 2 (1981) 173-177.

7. Gayton AC. Textbook of medical physiology. WB Saunders Company, Philadelphia PA 1981, pp 206-245.

8. Gemne G. Pathophysiology and multifactorial etiology of acquired vasospastic disease (Raynaud syndrome) in vibration-exposed workers. Scand J Work Environ Health 8 (1982) 243-249.

9. Gemne G, Pyykkö I, Starck J, Ilmarinen R. Circulatory reaction to heat and cold in vibration-induced white finger with and without sympathetic blockade - An experimental study. Scand J Work Environ Health 12 (1986) 371-377.

10. Ikehata K, Kawauchi S, Kohno F, Nishiyama M, Ide N. Increased platelet function and von Willebrand factor in vibration syndrome. Tokushima J Exp Med 27 (1980) $23-28$.

11. Janssens WJ, Vanhoutte PM. Effect of cooling on efflux of $\left({ }^{3} \mathrm{H}\right)$-noradrenaline in canine cutaneous veins. $\mathrm{J}$ Pharmacol 66 (1979) 148.

12. Lewis T, Pickering GW. Observations upon maladies in which the blood supply to digits ceases intermittently or permanently, and upon bilateral gangrene of digits; observations relevant to so-called "Raynaud's disease." Clin Sci 1 (1934) 327-366.

13. Matoba $T$, Kusumoto $H$, Kuwahara $H$, Ivanagak, Oshima M, Takamatsu M, Esaki K. Pathophysiology of vibration disease. Jpn J Ind Health 17 (1975) 11-18.

14. Nedergaard OA, Schrold J. The mechanism of action of nicotine on vascular adrenergic neuroeffector transmission. Eur J Pharmacol 42 (1977) 315-329.

15. Nicole PA, Webb RL. Vascular patterns and active vasomotion as determiners of flow through minute vessels. Angiology 6 (1955) 291-310.

16. Nielssen SL, Lassen NA. Measurement of digital blood pressure after local cooling. J Appl Physiol 43 (1977) 907-910.

17. Okada A, Yamashita T, Nagono C, Ikeda T, Yachi A, Shibata S. Studies on the diagnosis and pathogenesis of Raynaud's phenomenon of occupational origin. $\mathrm{Br} \mathrm{J}$ Ind Med 28 (1971) 353-357.

18. Olsen N, Fjeldborg P, Bröchner-Mortensen J. Sympathetic and local vasoconstrictor response to cold in vibration induced white finger. Br J Ind Med 42 (1985) 272-275.

19. Pyykkö I. The prevalence and symptoms of traumatic vasospastic disease among lumberjacks in Finland. Work Environ Health 11 (1974) 118-131.

20. Pyykkö I, Hyvärinen J. Vibration induced changes of sympathetic vasomotor tone. Acta Chir Scand Suppl 465 (1976) $23-26$.

21. Shephard JT, Vanhoutte PM. The human cardiovascular system. Raven Press, New York, NY 1980.

22. Stewart AM, Goda DF. Vibration syndrome. Br J Ind Med 27 (1970) 19-27.

23. Thulesius O, Brubaker A, Berlin E. Response of digital blood pressure to cold provocation in cases with Raynaud's phenomenon. Angiologia 32 (1981) 113-118.

24. Vanhoutte PM, Janssens WJ. Thermosensitivity of cutaneous vessels and Raynaud's disease. Am Heart J 100 (1980) 263-265.

25. Zelis R. Mechanisms of vasodilatation. Am J Med (1983) $3-12$. 